\title{
A PSO based Signal Timing Optimization Approach of Phase
}

\section{Combination}

\author{
Zhao Yuedong ${ }^{1,2, a}$ Fang Wei ${ }^{\star 3, b}$ Qing Chenchen ${ }^{2}$ \\ ${ }^{1}$ Wuhan University of Technology, Wuhan 430070, China; \\ ${ }^{2}$ The key Lab of Urban ITS Technology Optimization and Integration, Ministry of Public Security, \\ Hefei 230088, China; \\ ${ }^{3}$ Institute of Intelligent Machines, Chinese Academy of Sciences, Hefei 230031, China. \\ azhaoyuedong2016@sina.com \\ bwfang@iim.ac.cn
}

Keywords: traffic signals, phasing, particle swarm optimization, green split

Abstract: A signal timing optimization approach of phase combination on PSO (particle swarm optimization) is proposed in the paper. The objective function is to minimize the number of stops at intersection by combining the less different flow ratio of two streams into a team. The method is applied at the intersection of Huangshan road and Kexue Avenue of Hefei, China. It shows the number of stops is decreased about $19.04 \%$ through this phase combination. The total delay and CO emissions are also decreased by minimizing the number of stops. The method is effective in upgrading the traffic signal control program.

\section{Introduction}

With the development of city economic and population, cars increase and then traffic jam becomes sharp and serous in urban. Congestion results in low speed, increases traffic delay, travel time, fuel consumption, and brings air pollution problem. Intersection is the key joint of road network. Making traffic signal control more effective and optimal is a primary task to improve traffic management.

Lots of optimization methods have been studied in Intelligent transportation system(ITS), such as Genetic Algorithm(GA) ${ }^{[1],[2],[3]}$, Particle Swarm Optimization(PSO) ${ }^{[4],[5],[6]}$, Adaptive Traffic Signal Control ${ }^{[7]}$, phase sequence based method ${ }^{[8]}$ and Backpressure Traffic Control Algorithms ${ }^{[9]}$. Few of them discussed the optimal approach based on phase combination scheme. An Optimal method taking advantage of PSO based phase combination is proposed in the paper. The experiment shows that the stopped delay and fuel consumption is reduced simultaneously.

\section{Related work}

Phase combination

A standard 12 traffic flows of an intersection are shown in figure 1. No.9-12 which represents uncontrolled right turn flow was ignored here.

Signal phasing should be set as that non-conflicting traffic flows can be combined in one single phase, such as stream 1 and 2 means straight phase in East-West direction, 7 and 8 means left-turn phase in North-South direction and so on in Fig.1. According to non-conflicting traffic flows, the phasing could be set 7 combination groups as presented in table 1. Normally four phases make a 
signal phasing group and Group 1 is the most popular one.
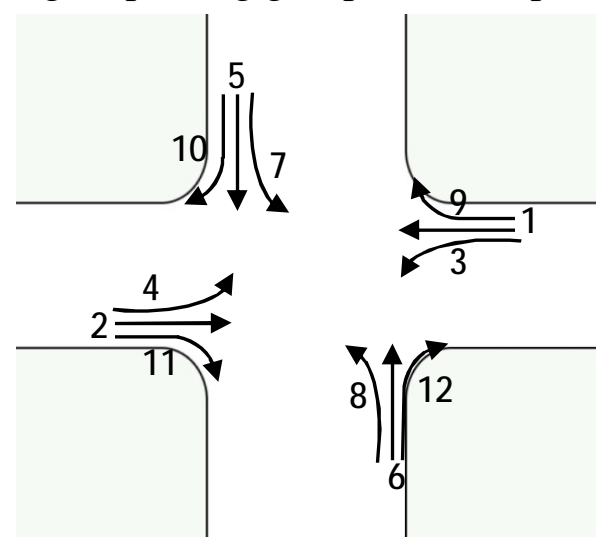

Fig.1 standard traffic flow of intersection

Tab. 1 Non-conflicting traffic flow in phasing group

\begin{tabular}{|c|c|c|c|c|}
\hline $\begin{array}{c}\text { No. of } \\
\text { flow }\end{array}$ & Phase 1 & Phase 2 & Phase 3 & Phase 4 \\
\cline { 1 - 4 } Group 1 & 1,2 & 3,4 & 5,6 & 7,8 \\
\hline Group 2 & 1,2 & 3,4 & 6,8 & 5,7 \\
\hline Group 3 & 1,3 & 2,4 & 5,6 & 7,8 \\
\hline Group 4 & 1,3 & 2,4 & 5,7 & 6,8 \\
\hline Group 5 & 1,2 & 3,5 & 6,4 & 7,8 \\
\hline Group 6 & 1,8 & 3,4 & 5,6 & 2,7 \\
\hline Group 7 & 3,5 & 1,8 & 4,6 & 2,7 \\
\hline
\end{tabular}

Model of Objective Functions

A low number of stops have larger positive impacts on exhaust emissions. In signal control measures, the goal of minimizing stops is deployed. The expression of stop frequency per vehicle widely used was given by Webster as:

$$
h_{i}=0.9 \frac{1-\lambda_{i}}{1-y_{i}}
$$

Subject to:

$$
\begin{aligned}
& 0.5 \leq y_{i} \leq 0.90 \\
& C \leq 180 \\
& 10 \leq g_{i} \leq 60
\end{aligned}
$$

Where, $i$ is the number of the phase, $h_{i}$ means stop frequency, $\lambda_{i}$ is the effective green split at $\mathrm{i}$-th phase, $\mathrm{y}_{\mathrm{i}}$ is the flow ratio at $\mathrm{i}$-th phase. $\mathrm{g}_{\mathrm{i}}$ is the effective green time at $\mathrm{i}$-th phase. $\mathrm{C}$ is the cycle length in second. The number of stops is expressed as:

$$
\mathrm{H}=\sum_{i=1}^{4} h_{i} q_{i} C
$$

Where, qi is the flow rate at $\mathrm{i}$-th phase.

PSO

Particle Swarm Optimization algorithm is an optimizing search method which simulates the 
behavior of birds looking for food. All the potential solutions in 7 groups are regarded as a point of a D-dimensional search space that is called "particle". Every particle has a fitness value determined by object function and a velocity to decide the flying direction and distance. The location and velocity are initiated randomly. Then all the particles change their position by each own previous best solution and the whole swarm's best solution.

Given total $n$ particles and $\mathrm{Q}$ dimension, the new velocity and the position of $\mathrm{i}$-th particle in d-th dimension is updated as follows:

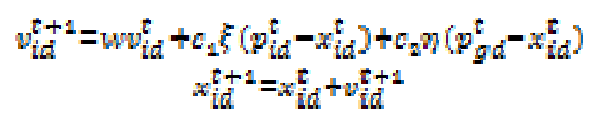

Where, $c_{1}$ and $c_{2}$ are cognitive and social weight parameter respectively. Generally $c_{1}$ and $c_{2}$ are set to 2 . $\xi$ and $\eta$ are random values between 0 and 1. $p_{\text {id }}$ is the previous best value of particle id. $\mathrm{p}_{\mathrm{gd}}$ is the global previous best value. In this paper $\mathrm{p}_{\mathrm{id}}$ and $\mathrm{p}_{\mathrm{gd}}$ denote the number of stops $\mathrm{H}$ expressed as (2). $\mathrm{x}_{\mathrm{id}}$ is the position of particle id. $\mathrm{w}$ is inertial factor that represents the acceleration of previous velocity and determines the speed of convergence. It is formulated as follows:

$$
w=w_{\max }-\frac{\text { aurrentloop } \cdot\left(w_{\max }-w_{\min }\right)}{\text { loopeount }}
$$

Where, the loopcount sets 200 in our program. The currentloop is the order number of current loop. The more $\mathrm{w}$ is, the faster the particles converge. In the application, the $\mathrm{x}_{\mathrm{id}}$ denotes the effective green time at i-th phase.

The program was running iteratively until to meet the minimum value of $\mathrm{H}$

\section{Experiment and discussion}

Taking intersection of Huanshan road and Kexue Ave. as an example depicted in Fig. 2 , the statistic of traffic streams from 5:00-6:00 pm is listed in table 2 (taking 1500PCU/h as saturation flow).

Table 2. statistics of traffic streams

\begin{tabular}{|c|c|c|c|}
\hline Traffic flow & flow rate $(\mathrm{pcu} / \mathrm{h})$ & No of lanes & Flow ratio \\
\hline 1 & 599 & 2 & 0.1997 \\
\hline 2 & 1021 & 2 & 0.3403 \\
\hline 3 & 196 & 2 & 0.0653 \\
\hline 4 & 104 & 1 & 0.0693 \\
\hline 5 & 335 & 2 & 0.1117 \\
\hline 6 & 282 & 2 & 0.094 \\
\hline 7 & 391 & 2 & 0.1303 \\
\hline 8 & 129 & 2 & 0.043 \\
\hline
\end{tabular}

The flow ratio of each phasing group for example group 1 is calculated as:

Phase 1: $y 1=\max (0.1997,0.3403)=0.3403$

Phase 2: $\mathrm{y} 2=\max (0.0653,0.0693)=0.0693$

Phase 3: $\mathrm{y} 3=\max (0.1117,0.0940)=0.1117$

Phase 4: $\mathrm{y} 4=\max (0.1303,0.043)=0.1303$ 


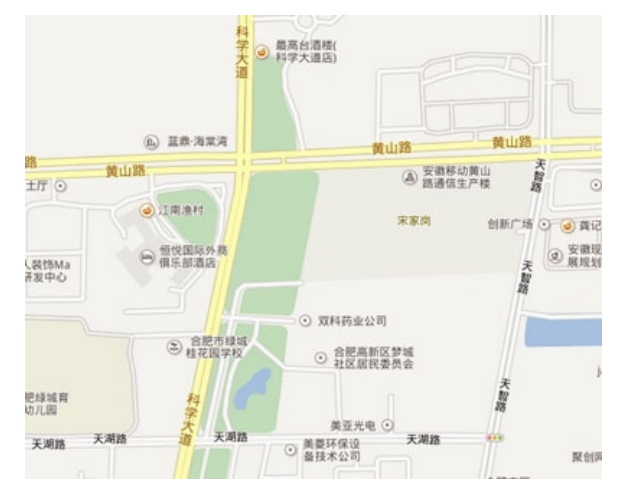

Fig. 2 intersection of huanshan road and Kexue ave. Hefei

The flow ratio of all phasing groups is listed in table 3.

Table 3. flow ratio

\begin{tabular}{|c|c|c|c|c|}
\hline $\begin{array}{c}\text { Flond } \\
\text { ratig }\end{array}$ & Phase 1 & Phase 2 & Phase 3 & Phase 4 \\
\hline Group 1 & 0.3403 & 0.0693 & 0.1117 & 0.1303 \\
\hline Group 2 & 0.3403 & 0.0693 & 0.094 & 0.1303 \\
\hline Group 3 & 0.1997 & 0.3403 & 0.1117 & 0.1303 \\
\hline Group 4 & 0.1997 & 0.3403 & 0.1303 & 0.094 \\
\hline Group 5 & 0.3403 & 0.1117 & 0.094 & 0.1303 \\
\hline Group 6 & 0.1997 & 0.0693 & 0.1117 & 0.3403 \\
\hline Group 7 & 0.1117 & 0.1997 & 0.094 & 0.3403 \\
\hline
\end{tabular}

In the experiment, the number of stops and effective green time of all groups are calculated using PSO algorithm and shown in table 4.

Table 4. The green split and the number of stops

\begin{tabular}{|c|c|c|c|c|c|c|c|}
\hline & \multirow{2}{*}{$\begin{array}{l}\text { number of } \\
\text { stops }\end{array}$} & \multicolumn{4}{|c|}{ Effective Green Time } & \multirow{2}{*}{$\begin{array}{l}\text { cycle } \\
\text { length }\end{array}$} & \multirow{2}{*}{$\begin{array}{c}\text { cycle flow } \\
\text { ratio }\end{array}$} \\
\hline & & $\mathrm{Ph} 1$ & $\mathrm{Ph} 2$ & $\mathrm{Ph} 3$ & $\mathrm{Ph} 4$ & & \\
\hline Group 1 & 43.6 & 45 & 11 & 16 & 19 & 107 & 0.6516 \\
\hline Group 2 & 35.3 & 35 & 10 & 11 & 13 & 85 & 0.6339 \\
\hline Group 3 & 74.4 & 50 & 30 & 16 & 19 & 131 & 0.7820 \\
\hline Group 4 & 74.7 & 55 & 32 & 20 & 15 & 138 & 0.7463 \\
\hline Group 5 & 48.6 & 19 & 40 & 11 & 16 & 102 & 0.6763 \\
\hline Group 6 & 62.4 & 14 & 29 & 17 & 55 & 131 & 0.7210 \\
\hline Group 7 & 72.1 & 33 & 17 & 16 & 55 & 137 & 0.7457 \\
\hline Transyt & 51.8 & 41 & 20 & 20 & 27 & 120 & 0.6516 \\
\hline
\end{tabular}

In tab.4 of last row it presents those data obtained by TRANSYT optimization tool for phasing group like group 1 in tab. 1. The cycle length 120s of TRANSYT equals sum of effective green time plus 12s amber flash time. Identically, cycle length of group 1-7 in tab.4 equals effective green time plus lost time 16s including amber flash time 12s. Comparing the results on first row and last row, the number of stops using PSO approach is reduced from 51.8 to 43.6 and the cycle length is reduced from 120 s to $107 \mathrm{~s}$. The reason might be that the PSO focus only on the number of stops, but the TRANSYT tries to optimize the stop frequency and the flow capacity simultaneously. 
Table 4 also shows that the optimization of phase combination plays role of advantages which the number of stops is reduced from 43.6 to 35.2 in Group 1 and Group 2 respectively as well as the cycle flow ratio of group 2 is the least in total groups.

The flow ratio in different phase combination is partially denoted as follows:

flow ratio of phase 3 in group $1: \mathrm{y} 3=\max (0.1117,0.0940)=0.1117$

flow ratio of phase 4 in group $1: \mathrm{y} 4=\max (0.1303,0.043)=0.1303$

flow ratio of phase 3 in group 2: $\mathrm{y} 3=\max (0.043,0.0940)=0.094$

flow ratio of phase 4 in group $2: \mathrm{y} 4=\max (0.1117,0.1303)=0.1303$

It was reasonable that phasing group 2 took the less different flow ratio of two streams to combine into a team.

Time delay and exhausted emission is discussed now. In signal timing model, the total delay is described by Webster as:

$$
D=\sum_{i=1}^{n} \mathrm{q}_{i} \mathrm{Cd}_{i}=\sum_{i=1}^{n} \mathrm{q}_{i} \frac{\left[\mathrm{C} \times\left(1-\mathrm{k}_{\mathrm{i}}\right]^{2}\right.}{2\left(1-y_{i}\right)}
$$

Where $D$ is the total delay, $d_{i}$ is the average delay per vehicle at $\mathrm{i}$-th phase.

The exhausted emission is proposed by Refs[10] as follows:

$$
E=\sum_{i=1}^{n}\left(E F_{i}^{P C V} \times q_{i} \times L_{0}\right)+\frac{1}{3600} \sum_{i=1}^{n}\left(E F I_{i}^{P C U} \times q_{i} \times d_{i}\right)
$$

Where, E is the pollutant emission. $E F_{i}^{P C U}$ is the pollutant discharge factor of i type vehicles. $E F I_{i}^{P C D}$ is idle speed pollutant discharge factor. $\mathrm{L}_{0}$ denotes the length of road entrance. Using known parameters in tab.3,4 the total delay and the $\mathrm{CO}$ emissions are calculated in table 5.

Table 5. the total delay and the CO emissions

\begin{tabular}{|c|c|c|}
\hline & Delay(s) & CO emissions $(\mathrm{g} / \mathrm{h})$ \\
\hline Group 1 & 1891.9 & 1786.8 \\
\hline Group 2 & 1878.0 & 1736.8 \\
\hline
\end{tabular}

From table 5 we can see the total delay and $\mathrm{CO}$ emissions are decreased in group 2 comparing with group 1.

\section{Conclusions}

In general, signal program designer picks up phasing groups by his/her experience then feeds corresponding parameters into optimization tool such as Transyt, PSO etc. to calculate. In the paper a PSO based signal timing optimization of phase combination approach provides an automatic select suitable phasing group method. The hints showed the less different flow ratio of two non-conflicting streams is suggested to be combined into one team. The object of optimizing is to minimize the number of stops in intersection of Huangshan road and Kexue Ave. in Hefei, China. The experiment shows the number of stops is decreased about $19.04 \%$ by optimal phase combination and total delay, $\mathrm{CO}$ emissions are also decreased.

In tab. 1 there are 7 normal phasing groups which do not include changing order of phase sequence as well as other complicated phasing situation for example with leading or lagging green. 
The impacts of slow moving such as pedestrian and cyclist should be considered either.

\section{Acknowledgements}

This work was supported by Helmholtz-CAS Joint Research Group under grant NO. HCJRG-303.

\section{References}

[1] Rami K. Abushehab, Baker K. Abdalhaq, Badie Sartawi. Genetic vs. Particle Swarm Optimization Techniques for Traffic Light Signals Timing. In IEEE International Conference on CSIT. (2014),p.27-35.

[2] L. Singh1, S.Tripathi2, H.Arora3,Time Optimization for Traffic Signal Control Using Genetic Algorithm, (2009).

[3] A.H. Farooqi, A.Munir and A. R. Baig, THE: traffic light simulator and optimization using Genetic Algorithm. ( 2009 ) .

[4] I Gede Pasek Suta Wijaya, Keiichi Uchimura, and Gou Koutaki, Traffic Light Signal Parameters Optimization Using Particle Swarm Optimization. In IEEE International Seminar on Intelligent Technology and Its Applications. (2015), p.11-16.

[5] Zhengbing He, Shoufeng Ma. Introduction to Applications of Swarm in Transportation Researches. In IEEE Fourth International Joint Conference on Computational Sciences and Optimization. (2011),p.1045-1048

[6] Jianjun Wu,Yubo Tan. A Particle Swarm Optimization Algorithm for Grain Logistics Vehicle Routing Problem. ISECS International Colloquium on Computing, Communication, Control, and Management. (2009),p.364-367.

[7] Igor Dakic, Jelka Stevanovic, Aleksandar Stevanovic. Backpressure Traffic Control Algorithms in Field-like Signal Operations. IEEE 18th International Conference on Intelligent Transportation Systems . (2015),p.137-142.

[8] Jason Barnes, Vamsi Paruchuri. Optimal Phase Ordering of Traffic Signals to reduce Stopped Delay. 26th IEEE International Conference on Advanced Information Networking and Applications. (2012), p.113-119.

[9] Michael P. Hunter, Seung Kook Wu, Hoe Kyoung Kim, and Wonho Suh. A Probe-Vehicle-Based Evaluation of Adaptive Traffic Signal Control. IEEE TRANSACTIONS ON INTELLIGENT TRANSPORTATION SYSTEMS, VOL. 13, NO. 2,( 2012), p.704-713

[10] Wang Fang. Research on signal timing of the road intersection based on low carbon transportation. [M] Hunan University.

[11] Code for Signal Control of Intersections on Urban Roads, DB 34/T 2423-2015, Local Standard of Anhui Province, China 